\title{
Evolutionary consequences of antibiotic use for the resistome, mobilome, and microbial pangenome
}

\author{
Michael R. Gillings* \\ Department of Biological Sciences, Macquarie University, Sydney, NSW, Australia
}

\section{Edited by:}

Fiona Walsh, Agroscope Changins

Wädenswil, Switzerland

Reviewed by:

Antonio Oliver, Hospital Son Dureta, Spain

Veljo Kisand, University of Tartu,

Estonia

${ }^{*}$ Correspondence:

Michael R. Gillings, Department of Biological Sciences, Macquarie University, Sydney, NSW

2109, Australia

e-mail: michael.gillings@mq.edu.au
The widespread use and abuse of antibiotic therapy has evolutionary and ecological consequences, some of which are only just beginning to be examined. One well known consequence is the fixation of mutations and lateral gene transfer (LGT) events that confer antibiotic resistance. Sequential selection events, driven by different classes of antibiotics, have resulted in the assembly of diverse resistance determinants and mobile DNAs into novel genetic elements of ever-growing complexity and flexibility. These novel plasmids, integrons, and genomic islands have now become fixed at high frequency in diverse cell lineages by human antibiotic use. Consequently they can be regarded as xenogenetic pollutants, analogous to xenobiotic compounds, but with the critical distinction that they replicate rather than degrade when released to pollute natural environments. Antibiotics themselves must also be regarded as pollutants, since human production overwhelms natural synthesis, and a major proportion of ingested antibiotic is excreted unchanged into waste streams. Such antibiotic pollutants have non-target effects, raising the general rates of mutation, recombination, and LGT in all the microbiome, and simultaneously providing the selective force to fix such changes. This has the consequence of recruiting more genes into the resistome and mobilome, and of increasing the overlap between these two components of microbial genomes. Thus the human use and environmental release of antibiotics is having second order effects on the microbial world, because these small molecules act as drivers of bacterial evolution. Continued pollution with both xenogenetic elements and the selective agents that fix such elements in populations has potentially adverse consequences for human welfare.

Keywords: metagenomics, evolvability, pollution, pangenome, resistome, parvome, mobilome

\section{INTRODUCTION}

The discovery of antibiotics and their use in the treatment of bacterial infections was one of the major scientific achievements of the 20th century. However, over the last 60 years, there has been a spectacular and rapid evolution of antibiotic resistant strains of bacteria. This has culminated in the appearance of pathogens with resistance to a wide range of antibiotics, and a rise of similarly resistant opportunistic organisms (Davies, 2007; Davies and Davies, 2010). Antibiotic resistance is a critical problem for humans and their domestic animals, and is recognized as such by workers in government, clinical practice, research, and industry (Bush et al., 2011).

The focus of research and thinking about this problem has mainly been from an anthropogenic viewpoint. However, at its heart, antibiotic resistance is an environmental and evolutionary problem. Humans are now the greatest evolutionary force on the planet (Palumbi, 2001), and it would help us understand and manage the resistance problem to investigate resistance from a broader perspective, most notably in terms of the interplay between ecology, evolutionary dynamics, and natural selection. A number of authors are now thinking about the ecology and natural history of antibiotics and resistance genes. This approach will inform clinical and veterinary practices and will improve our understanding of evolutionary processes (Aminov and
Mackie, 2007; Baquero et al., 2009; Fajardo et al., 2009; Stokes and Gillings, 2011).

There is evidence that the antibiotic revolution may have second order effects, and is influencing the evolution of the entire microbial biosphere (Martinez, 2008; Baquero, 2009; Couce and Blázquez, 2009; Gillings and Stokes, 2012). This paper attempts to place antibiotics, resistance genes, their vectors, and their hosts into an evolutionary perspective. By understanding the evolutionary history of these genes and molecules, we place ourselves in a better position to predict their future (Martinez et al., 2007; Courvalin, 2008; Conway Morris, 2010).

\section{THE NATURAL HISTORY OF ANTIBIOTICS}

The term "antibiotic" reflects our anthropocentric viewpoint. Antibiotics are not a discrete class of molecules, but rather, encompass a broad range of structural and molecular families, united by their ability to inhibit microbial growth at high concentrations. The original use of the word "antibiotic" was a generic term that simply reflected the outcome of a laboratory test (Waksman, 1973; Davies and Davies, 2010). In modern terms, an antibiotic has broadly come to mean any synthetic or naturally occurring low molecular weight molecule that inhibits bacterial growth.

It is clear that there are millions of low molecular weight compounds in natural environments, and that in high enough 
concentrations some of these could exhibit an antibiotic effect. However, it is unlikely that such compounds ever reach inhibitory concentrations in nature, and there is a growing realization that their primary role is not necessarily in cross-species warfare, but may largely lie in cell-cell communication (Linares et al., 2006). This change in viewpoint began with the discovery of bacterial quorum sensing, a system that allows communication between cells of the same or different species via signaling molecules called auto-inducers. Quorum sensing is found in diverse organisms, and the scale and extent of signaling systems in general has led to the revelation that the microbial world is in a state of constant and complex communication (Lyon and Muir, 2003; Henke and Bassler, 2004; Stevens et al., 2012). Consequently, many of the small molecules produced by bacteria may be involved in additional forms of communication between cells. The compounds we know as "antibiotics" are a minor subset of this world of small molecules.

The growth-inhibiting concentrations of antibiotics used in clinical practice are unlikely to ever be reached via natural synthesis, and consequently, antibiotics probably have significant effects at sub-inhibitory concentrations, without affecting bacterial growth rates. It has now been shown that sub-inhibitory concentrations of various antibiotic classes have effects on gene transcription. Up regulation and down regulation of diverse genes has been demonstrated, with some estimates suggesting that as many as $5 \%$ of gene promoters might be affected (Goh et al., 2002; Linares etal., 2006). Some antibiotic classes modulate expression of particular genes (Tsui et al., 2004). The types of functions affected are diverse, including genes for protein synthesis, carbohydrate metabolism, transport/binding proteins and genes of as yet unknown function (Goh et al., 2002; Lin et al., 2005).

The cascade of gene expression induced by sub-inhibitory concentrations of antibiotics leads to phenotypes of adaptive significance. These include flagella biosynthesis and the ability to colonize biotic and abiotic surfaces (Seshasayee et al., 2006). As might be expected, some of these phenotypes have direct relevance for species-species interactions and responses to host cells, such as virulence, biofilm formation, and motility (Goh et al., 2002; Hoffman et al., 2005; Linares et al., 2006; Marr et al., 2007; Shank and Kolter, 2009). Collectively, these observations strongly suggest that the antibiotics used in medical treatment are a small subset of the diverse secondary metabolites used in the microbial world for signaling and other cell-cell interactions. Their clinical use is based on a serendipitous ability to inhibit growth at unnaturally high concentrations. There is a growing realization that the discovery, clinical use, and evolution of antibiotics must be considered against the background of their roles in natural environments (Davies et al., 2006; Yim et al., 2007; Fajardo and Martínez, 2008; Ryan and Dow, 2008).

\section{A GENERIC MODEL OF SMALL MOLECULE SIGNALING}

Thinking about antibiotics as a subset of signaling molecules allows us to construct simple conceptual models that might establish some general principles about antibiotics and antibiotic resistance (Figure 1). A signaling molecule must be made by a metabolic pathway, whose enzymes are encoded by genes $(A$, $B$, and $C$ in Figure 1). Any intermediate small molecule in this pathway can be exported as a signaling molecule, most probably using an efflux pump. Small molecules then diffuse into environmental space, where they can bind to receptors on the cell surface of the producing species (intra-species signaling), or to cell surface receptors of different species (inter-species signaling). Alternatively, small molecules can be imported into cells via a membrane transport protein, and then bind to a target within the cell (Figure 1). Binding of signaling molecules can influence transcription or biochemical pathways, and thus affect the phenotypic attributes of the receptor cell.

This conceptual model (Figure 1) allows us to consider antibiotics and resistance from a different and broader perspective. Antibiotics can be thought of as a subset of small biosynthetic molecules, albeit those which happen to have the property of inhibiting bacterial growth at high concentrations. Given the fact that bacteria have been evolving and interacting for some 3.8 billion years, it should not be surprising that the genes encoding biosynthetic and catabolic pathways for small molecules have an ancient evolutionary history. Pathways for synthesis of erythromycin and streptomycin date to more than 600 million years ago (Baltz, 2005), and it has been estimated that the serine $\beta$ lactamases date back 2 billion years (Hall and Barlow, 2004). Under this view "antibiotics" predate humans by some billions of years.

Note that the use of an intermediate in the biosynthetic pathway as a signaling molecule (Figure 1, triangle) means that

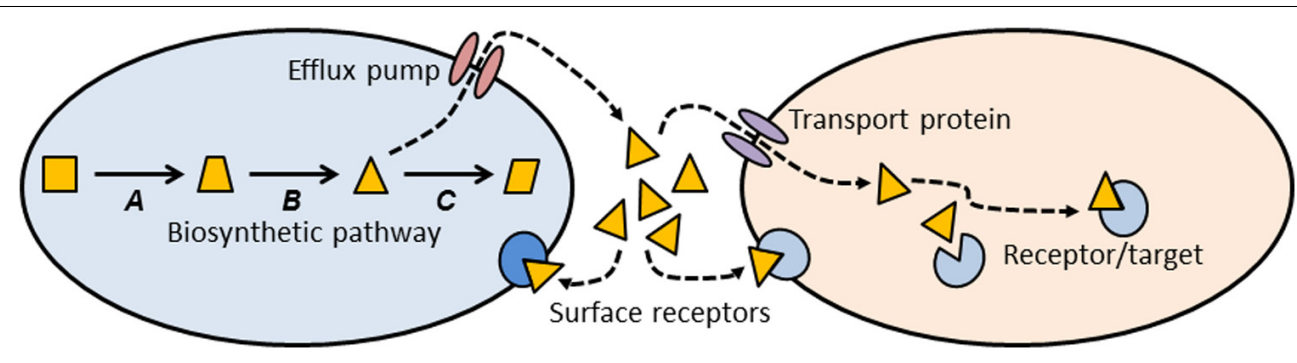

FIGURE 1 | Conceptual schematic illustrating the production, export, and target sites of a small molecule biosynthetic cluster. The metabolic pathway for synthesis of a small molecule is encoded by genes $A, B$, and $C$. One of the intermediates (triangle) is exported from the cell via an efflux pump, where it can then bind to cell surface receptors, or enter a second cell via a membrane transport protein. Inside the second cell there may be binding sites on additional target molecules. Most of the molecules we know as antibiotics may be a subset of this more general class of signal-receptor systems. 
the producing cell already encodes an enzyme capable of modifying the signal molecule. Under other circumstances, such a gene might confer resistance to high concentrations of the agent. Many biosynthetic gene clusters that make "antibiotics" are also known contain genes that confer "resistance" to those same antibiotics (Pootoolal et al., 2002; Huang et al., 2005). Given that gene clusters for secreted molecules are frequently subject to lateral gene transfer (LGT; Fischbach et al., 2008; Nogueira et al., 2009), it should not be surprising that there is clear evidence for lateral transfer of antibiotic resistance genes from environmental bacteria into pathogens (Gillings et al., 2008a,b; Forsberg et al., 2012).

Small molecules can exit the producing cell via a wide diversity of membrane bound efflux pumps (Figure 1; Paulsen et al., 1996; Desvaux et al., 2004; Poole, 2005; Bay and Turner, 2009), each of which, in turn, may be able to export diverse molecular species (Zgurskaya and Nikaido, 2000; Kuete et al., 2011). Such pumps have evolved as mechanisms to export natural substances produced internally, or those that are produced by other cells (Martinez et al., 2009b). Efflux pumps may also be essential for colonizing and persisting in eukaryotic hosts (Piddock, 2006). It is thus clear that antibiotic resistance mediated by efflux pumps is a side-effect of a more general molecular export system.

Genes for efflux pumps are commonly found in bacteria that produce antibiotics (Petković et al., 2006), and these genes are often found embedded within biosynthetic gene clusters for antibiotics, thus conferring efflux ability (and "resistance") on the producing organism (Méndez and Salas, 2001). Again, the "resistance" gene is preexistent, and located within a gene cluster characterized by LGT (Nogueira et al., 2009).

Once exported from the cell, a signaling molecule is free to bind with receptors on the surface of neighboring cells (Figure 1). Point mutations in the genes for these receptors might alter the binding site and thus generate a "resistance" phenotype. Alternatively, the signaling molecule may be taken up by a membrane transport protein and imported into a new cell. A surprising diversity of bacteria make use of such transport proteins to import small molecules such as antibiotics, which they can then use as a sole carbon source (Dantas et al., 2008). Lateral transfer of the genes for such catabolic processes would confer resistance on the recipient cell. Resistance could also be generated by mutation to the gene encoding the membrane transport protein, preventing entry of the signaling molecule. Once inside a recipient cell, a signaling molecule may bind to a target site, and thus exert an effect. Mutation of the gene encoding the target site may abolish binding and prevent the effect. In the case of an antibiotic, such a change would be called a resistance mutation.

Although the model I have presented above is simplistic, nevertheless it has good explanatory power for understanding the ecology and evolution of both antibiotics and their corresponding resistance genes. Antibiotics are seen as a subset of a diverse group of small molecules whose primary function is in cell-cell interactions. Genes for synthesizing, transporting, and catabolizing these small molecules can be co-opted as resistance genes when cells are exposed to unnaturally high concentrations of these compounds. The high frequency of lateral exchange of biosynthetic gene clusters for small molecules (together with their associated efflux pumps and catabolic functions) explains the penetration of efflux pumps and degradative enzymes into species unrelated to the original "antibiotic" producer.

\section{ANTIBIOTICS, RESISTANCE GENES, AND THE GLOBAL MICROBIOME}

In thinking about the ecology and evolution of antibiotics and resistance genes, we can summarize the sub-components upon which selection can act in a series of Venn diagrams (Figure 2). The largest category is the Global Microbiome, encompassing all the prokaryotic cells in the biosphere. This may contain 4-6 $\times 10^{30}$ cells and hold a significant proportion of the carbon, nitrogen, and phosphorus found in living things (Whitman et al., 1998). The phenotypes exhibited by the global microbiome are encoded by the microbial Pangenome, that is, the set of genes present in all the genomes of all the prokaryotes in the biosphere (Medini et al., 2005; Tettelin et al., 2008; Lapierre and Gogarten, 2009). Estimates of the composition of the pangenome have been made, based on the rapid accumulation of bacterial genome and metagenome sequences. Some 250 gene families are common to all bacterial genomes (the extended core genome) and about 8,000 gene families are niche-specific genes essential for survival in particular environments (the character genome). The bulk of pangenomic diversity comprises more than 139,000 gene families that occur as accessory genes, these being found dispersed amongst single strains, serovars or species (Lapierre and Gogarten, 2009). The combined coding capacity of the pangenome is expressed as the Panproteome, this being the sum of all the proteins encoded and produced by the microbial realm.

A proportion of the pangenome is highly mobile, and able to move comparatively freely between prokaryote species in the process known as LGT. Elements that specialize in moving DNA within and between genomes include plasmids, transposons, integrons, insertion sequences, and integrative conjugative elements. These elements and the genes they carry are collectively known as the Mobilome (Figure 2; Siefert, 2009; Leplae et al., 2010). In principle, and over evolutionary timescales, any part of the pangenome can be mobilized by LGT. The mobilome helps to generate enormous diversity within prokaryote genomes by recombination between various mobile elements to create a series of complex mosaic structures (Garriss et al., 2009; Toleman and Walsh, 2011; Toussaint and Chandler, 2012).

The Resistome is defined as the collection of all genes that could contribute to a phenotype of antibiotic resistance (D'Costa et al., 2006; Wright, 2007, 2010; Forsberg et al., 2012). This is a purely functional definition made from a human and medical point of view, for as we have seen, the resistome encompasses diverse genes whose original functions were not simply for avoiding the effects of antibiotics. Nevertheless, it is a useful concept, because it underscores the point that resistance genes originate from environmental bacteria. A database of antibiotic resistance genes has been developed (Liu and Pop, 2009), but the 20,000 genes already listed are only a small proportion of the resistome, since investigation of soil metagenomes has revealed diverse and divergent resistance genes capable of dealing with multiple classes of antibiotic (Riesenfeld et al., 2004; Allen et al., 2008). Genes encoding 


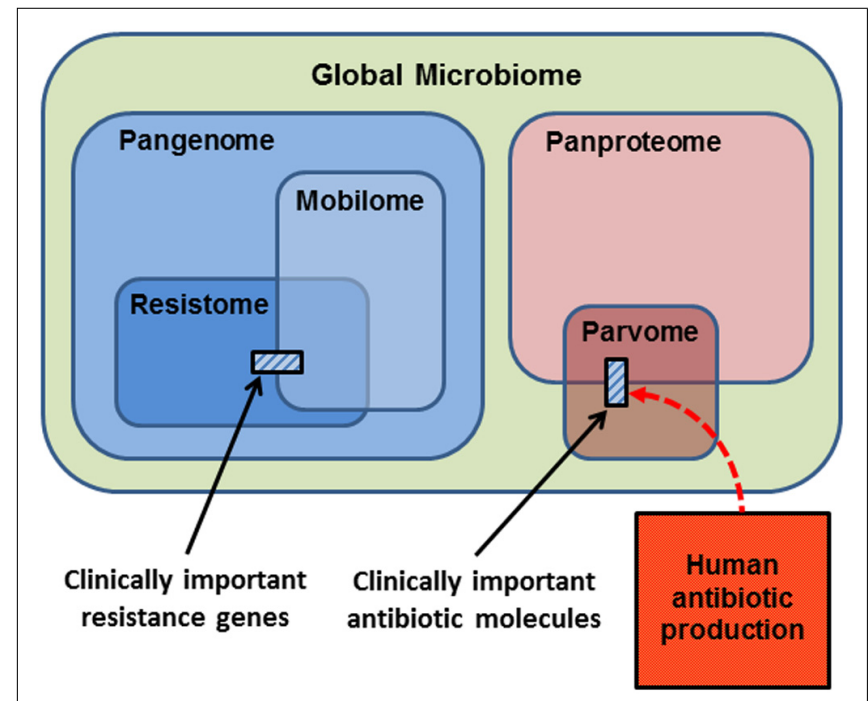

FIGURE 2 | Conceptual representation of the biological molecules of relevance to antibiotic resistance. The small cross-hatched boxes represent the antibiotics and resistance genes of relevance to clinical practice. Respectively, these are a small subset of the world of small bioactive molecules (the parvome), and the world of potential resistance determinants (the resistome). The resistome comprises the genes that potentially encode resistance to antibiotics. The mobilome comprises the mobile proportion of bacterial genomes. The mobilome and resistome overlap, since many resistance genes are located on mobile elements. Both the resistome and mobilome are a subset of the total coding capacity of prokaryotic cells, the pangenome, which is expressed as the panproteome. Note that only a small proportion of the parvome is utilized by humans for antibiotic purposes, and that the scale of commercial antibiotic production probably overwhelms the natural production of these molecules by the entire global microbiota.

antibiotic resistance are ancient components of the pangenome, since they have been recovered from 30,000 year old permafrost (D'Costa et al., 2011), and from a cave microbiome that has been isolated for 4 million years (Bhullar et al., 2012). Note that the resistome overlaps with the mobilome (Figure 2), because many antibiotic resistance genes are found on mobile elements, allowing the resistome to be widely disseminated by LGT (Norman et al., 2009; Fondi and Fani, 2010; Skippington and Ragan, 2011). Also note that the resistance genes and mobile elements that are of concern for clinical antibiotic resistance (cross-hatched box, left hand side Figure 2) are just a fraction of the resistome and mobilome.

The Parvome is the world of small bioactive molecules produced by cells (also sometimes called secondary metabolites). The parvome includes important classes of molecules such as polyketides, aminoglycosides, terpenoids, alkaloids, and non-ribosomal peptides, many of which have antimicrobial activity (Davies, 2011; Davies and Ryan, 2011). The parvome overlaps with the proteome, because some of these small bioactive molecules are peptides. Note however, that only a small proportion of the parvome is utilized by humans for its antimicrobial properties (cross-hatched box, right hand side Figure 2). Commercial production of antibiotics overwhelms their natural synthesis, such that humans are now the major source of antibiotics in the general environment (Figure 2; Sarmah et al., 2006; Davies and Davies, 2010).

\section{EVOLUTIONARY CONSEQUENCES OF THE ANTIBIOTIC AGE}

Having examined the relationships between the key components of relevance to antibiotic production and resistance (Figure 2), we can now examine how each might be affected by human activity. There are several potential dimensions to these effects, including changes to the abundance and diversity of each component, and whether the effects are transient or permanent.

\section{THE PARVOME}

Antibiotics are released into the environment via human waste streams because a significant proportion of prophylactic antibiotics are excreted essentially unchanged (Sarmah et al., 2006; Le-Minh et al., 2010). Although it is difficult to obtain precise estimates for commercial production of antibiotics, it probably amounts to millions of metric tons per year (Segura et al., 2009). Because of the volume of antibiotics generated by human activity, the majority of the environmental load of antibiotics now originates from this commercial production (Figure 2; Davies and Davies, 2010). Certainly the local concentrations of this subset of the parvome have markedly increased due to human activity. Further, the diversity of small bioactive molecules has increased, because many antibiotics are synthetic modifications of natural structures. There is now a zone of influence around all human activities where the abundance and diversity of the parvome is increased. Such zones increase selective pressures on the local microbiome, not just the intended targets of antibiotic therapy (Martinez et al., 2009a; Taylor et al., 2011), and may also interfere with cell-cell communication.

\section{THE RESISTOME}

Increasing the concentration of antibiotics in the environment has effects on both the diversity and the abundance of genes belonging to the resistome. Selection for cells that carry resistance determinants increases their relative abundance, and thus increases the abundance of genes that confer resistance. Further, the ability of many elements of the resistome to undergo LGT, means that identical resistance genes can now be found in diverse bacterial species, from clinical contexts, from domestic animals, wild animals, and in locations apparently distant from the influence of developed societies, such as the Arctic, Antarctica, and the Amazonian jungle (Pallecchi et al., 2008; Sjolund et al., 2008; Bartoloni et al., 2009; Stokes and Gillings, 2011). That humans are responsible for this phenomenon is demonstrated by the positive correlation between the abundance of resistome elements of clinical significance and proximity to human activity (Skurnik et al., 2006; Hardwick et al., 2008; Thaller et al., 2010; Nardelli et al., 2012).

Selection pressure is particularly acute in human waste streams, where resistance genes are shed, mixed with high concentrations of antibiotics and other selective agents (Baquero et al., 2008; Schlüter et al., 2008; Moura et al., 2010). Exposure of environmental microorganisms to this mixture encourages fixation of LGT events, spreading elements of the resistome into diverse strains and species, thus further increasing their abundance, and their penetration into new hosts and niches.

Exposure to sub-inhibitory concentrations of antibiotics induces expression of error-prone DNA polymerases, increasing 
the basal mutation rate (Kohanski et al., 2010; Thi et al., 2011). This has the effect of generating additional genomic diversity, and of co-opting additional genes into the resistome via mutational changes to housekeeping or accessory genes whose original function was not antibiotic resistance (Dantas and Sommer, 2012). As a second order effect, constant low level antibiotic exposure selects for lineages with inherently higher rates of mutation, generating additional diversity across the entire pangenome via drift and selection (Earl and Deem, 2004; Pigliucci, 2008; Couce and Blázquez, 2009; Gillings and Stokes, 2012).

Human activity has increased the abundance of resistome elements by selection, as shown by their increase in frequency in soils collected over the last 70 years (Knapp et al., 2009), and by their lateral transfer to diverse species. We have also increased the diversity and membership of the resistome by fixation of de novo mutations and by the co-option of genes as resistance determinants. Thus the size of the resistome, as a proportion of the pangenome, is probably becoming larger (Figure 2).

\section{THE MOBILOME}

The clinical use and environmental dissemination of antibiotics has had significant effects on the abundance and diversity of elements within the mobilome. Selection for antibiotic resistance has fixed lineages carrying diverse resistance determinants on a similarly diverse array of mobile elements. Such complex mobile elements now occur at high frequency in human-dominated systems, and in more natural ecosystems, where they can move by LGT into environmental organisms (Chee-Sanford et al., 2001; Nagachinta and Chen, 2008; Schlüter et al., 2008; Gillings et al., 2009a; Pellegrini et al., 2009).

The very use of antibiotics may itself increase the frequency of LGT, and thus the penetration of elements of the mobilome into new bacterial hosts (Beaber et al., 2004; Úbeda et al., 2005; Prudhomme et al., 2006). This effect is driven by the bacterial SOS response, which temporarily increases both the basal rate of LGT and of recombination (Tenaillon et al., 2004; Schlacher and Goodman, 2007). There is also evidence that human activities actually select for bacteria with a permanently increased propensity for LGT (Gillings and Stokes, 2012). Consequently, antibiotic pollution creates hotspots for the assembly of complex, mosaic mobile elements from diverse sources, and provides a selective force for their subsequent fixation in diverse lineages (Szczepanowski et al., 2005; Schlüter et al., 2008; Gillings et al., 2009b).

The accumulation of diverse mobile elements within single plasmids or at single loci provides opportunities for complex rearrangements and recombination events that in turn, generate more diversity (Garriss et al., 2009). The emergent properties that arise as mobile elements gain more components means that they can effectively increase their own complexity (Krizova et al., 2011; Toleman and Walsh, 2011). This phenomenon is evident in the increasing complexity and phenotypic plasticity of genomic islands and integrative conjugative elements in emerging nosocomial pathogens such as Pseudomonas aeruginosa and Acinetobacter baumannii (Fournier et al., 2006; Klockgether et al., 2011).

The selective forces acting upon complex mobile elements are not restricted to antibiotic pressure. Mobile DNAs often carry genes conferring resistance to other selective agents, such as heavy metals, arsenic, and disinfectants. Exposure to any one of these agents selects for lineages containing mobile elements with appropriate resistance genes, and simultaneously fixes all the other genes in physical linkage on that element, including antibiotic resistance determinants. Such co-selection of antibiotic resistance has long been thought to arise as a consequence of pollution with heavy metals (Baker-Austin et al., 2006; Salyers and Shoemaker, 2006; Stepanauskas et al., 2006; Wright et al., 2008; Rosewarne et al., 2010; Drudge et al., 2012). Disinfectant use also results in co-selection of antibiotic resistance (Gaze et al., 2005; Hegstad et al., 2010), and probably had a role in the origin of the class 1 integrons responsible for the widespread dissemination of antibiotic resistance amongst gram negative organisms (Gillings et al., 2008b).

High rates of LGT occur between organisms in similar Phyla, organisms with similar GC content, and organisms that occupy the same environmental niches (Thomas and Nielsen, 2005; Popa and Dagan, 2011). This activity creates lateral exchange communities, where DNA can be exchanged with relative ease (Beiko et al., 2005; Kloesges et al., 2010; Skippington and Ragan, 2011). Shared niches, and in particular, biofilms, promote such exchanges (Sorensen et al., 2005), and both conjugation and natural transformation appear to be important in the process (Kloesges et al., 2010; Domingues et al., 2012). While evolutionary distance and difference in GC content can restrict LGT, there are mechanisms for bypassing these barriers (Popa et al., 2011), and genes can make their way between distantly related organisms via a sequential series of lateral transfers.

Human use of antibiotics is therefore having multiple effects on the mobile components of the bacterial pangenome. One would predict that the size of the mobilome as a proportion of the pangenome is becoming larger, as more genes are recruited onto mobile elements (Figure 2). The number of resistome elements now residing on mobile DNA is also increasing, given that plasmids collected before the antibiotic era had no resistance determinants (Datta and Hughes, 1983; Hughes and Datta, 1983), and modern plasmids of similar structure have acquired a wide range of resistance genes dealing with various selective agents in addition to antibiotics. Consequently, there is now a greater overlap between the resistome and mobilome, particularly with respect to genes of concern for human health and welfare (Figure 2).

\section{THE PANGENOME AND GLOBAL MICROBIOME}

Human antibiotic use has pervasive effects on both the pangenome and the local composition of the microbiome, largely because antibiotics have non-target effects at gene, cell, and population levels. Exposure of cells to antibiotics induces an SOS response that has widespread effects on bacterial genomes, including raising the rates of mutation, recombination, and LGT (Tenaillon et al., 2004; Aertsen and Michiels, 2006; Schlacher and Goodman, 2007). This increase in basal rates of evolution applies to all the genes and cells in the exposed environment, not just the targets of antibiotic therapy. Consequently, the release of antibiotics into natural environments will affect the diversity of the pangenome and the composition and ecology of the global microbiota (Couce and Blázquez, 2009; Martinez, 2009a; Gillings and Stokes, 2012). 
Effects in particular environments have been demonstrated experimentally. Short term antibiotic treatments lead to changes in abundance, richness, and diversity of the human gut microbiota (Dethlefsen et al., 2008), which can remain perturbed for years after treatment (Jakobsson et al., 2010; Sommer and Dantas, 2011). The composition and functional diversity of soil and sediment communities is affected by exposure to antibiotics (Kong et al., 2006; Cordova-Kreylos and Scow, 2007), and persistence of antibiotic residues in sediments or in the water column leads to alteration of microbiota and in situ selection for antibiotic resistance (Cabello, 2006; Knapp et al., 2008). While pulses of exposure to antibiotics may only produce transient selection events, alterations to community composition, and the fixation of resistance genes and their mobile vectors may be permanent, with unpredictable consequences for the whole microbiome (Martinez, 2009b; Gillings and Stokes, 2012).

\section{ANTIBIOTICS AND RESISTANCE GENES AS POLLUTANTS}

Antibiotics and their resistance genes originated from natural environments, but human use of antibiotics has perturbed the dynamics of this natural system. The high concentration of antibiotics used prophylactically by humans has two main consequences. Firstly, it leads to antibiotic contamination of human waste streams, and secondly, the selection imposed by antibiotic use has fixed ever more complex genetic elements in commensals and pathogens. These new "xenogenetic" elements are also released via human waste streams. While antibiotics might be treated as simple pollutants, xenogenetic mobile elements are capable of replication, and are thus more akin to invasive species (Gillings and Stokes, 2012).

Between 30 and $90 \%$ of the antibiotics given for human or veterinary use are excreted essentially unchanged (Sarmah et al., 2006). These compounds can be both persistent and mobile, and are often not removed during sewage treatment (Watkinson et al., 2007; Le-Minh et al., 2010; Zuccato et al., 2010). Antibiotics are also released in high concentrations from facilities where antibiotics are produced (Li et al., 2009, 2010), and are disseminated during application of manure to agricultural land (Chee-Sanford et al., 2009; Heuer et al., 2011). The consequences of pollution with antibiotics, particularly for aquatic systems, are being actively examined (Taylor et al., 2011; Lupo et al., 2012), and there is a call for development of policies to reduce the release of antibiotics and bacteria via human waste streams (Baquero et al., 2008).

Waste streams that release antibiotics into the environment also disseminate antibiotic resistance genes and mobile DNA elements, which should similarly be regarded as pollutants emanating from human activity (Pruden et al., 2006; Martinez, 2009a; Storteboom etal., 2010; Graham etal., 2011). The abundance of resistance genes in soils has been increasing since the introduction of antibiotics in the 1940s (Knapp et al., 2009), in parallel with the increasing concentrations of more conventional chemical pollutants.

Resistance genes and complex mobile elements are commonly reported from wastewater and sewage treatment plants (Tennstedt et al., 2003; Zhang et al., 2009; Pellegrini et al., 2011). Wastewater is regarded as a hotspot for interactions between mobile elements and for their lateral transfer between pathogens, commensals, and environmental bacteria (Schlüter et al., 2008; Moura et al., 2010). Resistome and mobilome elements are not necessarily removed by water treatment (Graham etal., 2011; Drudge et al., 2012), allowing resistance genes to be used as markers of human influence on aquatic ecosystems (Pei et al., 2006; Pruden et al., 2006; Storteboom et al., 2010).

Domestic and agricultural animals are a source of significant quantities of antibiotics and resistance genes. Animal waste and pig slurry are used to manure soils, with the consequent introduction of resistance genes and resistant bacteria (Binh et al., 2009; Byrne-Bailey et al., 2009; Gaze et al., 2011). The long term fate of antibiotics and resistance genes is difficult to predict without quantitative measurements over appropriate timescales (Chee-Sanford et al., 2009). However, it is clear that antibiotic resistant bacteria will increase in abundance, lateral transfers to soil organisms will occur, and resistance genes will be sequestered by diverse elements of the mobilome (Heuer et al., 2011).

\section{CONCLUSION}

Human use of antibiotics for medicine and agriculture may have consequences beyond their intended applications. Large quantities of antibiotics now emanate from human waste streams, as do the xenogenetic elements fixed in human ecosystems by antibiotic selection. Much more attention needs to be paid to the origins and fates of such pollutants (Allen et al., 2010). The antibiotic revolution may be having effects across the entire microbial biosphere (Martinez, 2009b), changing the basal rate of bacterial evolution, altering the composition of the resistome and mobilome, and promoting lateral transfer of mobile genetic elements (Couce and Blázquez, 2009; Gillings and Stokes, 2012). Antibiotic contamination promotes the fixation and mobilization of resistance genes between environmental and clinical microbiota (Kristiansson et al., 2011), and resistance genes are now widely spread through the biosphere (Martinez, 2009a; Stokes and Gillings, 2011).

Above all, we need to address the antibiotic resistance problem from a broader evolutionary and ecological perspective (Aminov and Mackie, 2007; Baquero et al., 2009; Fajardo et al., 2009). The ability of natural selection to shape species and communities is the same for microorganisms as it is for larger species (Gillings and Stokes, 2012), and the ecological theory of community assembly developed for multicellular organisms can be applied to the microbiome (Costello et al., 2012). The risk associated with the environmental spread of resistance genes with known adverse consequences for human welfare has had little attention, nor has the potential for pollution with antibiotics to widely affect the global microbiome. In comparison, the potential escape of resistance gene markers used in the generation of genetically modified plants has been the subject of considerable research (Martinez, 2012). It is time to pay more attention to the bioactive molecules that humans release into the environment.

\section{ACKNOWLEDGMENTS}

Aspects of the author's work are supported by the Australian Research Council, the National Health and Medical Research Council of Australia and Macquarie University. 


\section{REFERENCES}

Aertsen, A., and Michiels, C. W. (2006). Upstream of the SOS response: figure out the trigger. Trends Microbiol. 14 421-423.

Allen, H. K., Donato, J., Wang, H. H., Cloud-Hansen, K. A., Davies, J., and Handelsman, J. (2010). Call of the wild: antibiotic resistance genes in natural environments. Nat. Rev. Microbiol. 8, 251-259.

Allen, H. K., Moe, L. A., Rodbumrer, J., Gaarder, A., and Handelsman, J. (2008). Functional metagenomics reveals diverse $\beta$-lactamases in a remote Alaskan soil. ISME J. 3, 243-251.

Aminov, R. I., and Mackie, R. I. (2007). Evolution and ecology of antibiotic resistance genes. FEMS Microbiol. Lett. 271, 147-161.

Baker-Austin, C., Wright, M. S., Stepanauskas, R., and McArthur, J. V. (2006). Co-selection of antibiotic and metal resistance. Trends Microbiol. 14, 176-182.

Baltz, R. H. (2005). Antibiotic discovery from actinomycetes: will a renaissance follow the decline and fall? SIM News 55, 186-196.

Baquero, F. (2009). Environmental stress and evolvability in microbial systems. Clin. Microbiol. Infect. 15, 5-10.

Baquero, F., Alvarez-Ortega, C., and Martinez, J. L. (2009). Ecology and evolution of antibiotic resistance. Environ. Microbiol. Rep. 1, 469-476.

Baquero, F., Martínez, J.-L., and Cantón, R. (2008). Antibiotics and antibiotic resistance in water environments. Curr. Opin. Biotechnol. 19, 260-265.

Bartoloni, A., Pallecchi, L., Rodríguez, H., Fernandez, C., Mantella, A., Bartalesi, F., et al. (2009). Antibiotic resistance in a very remote Amazonas community. Int. J. Antimicrob. Agents 33, 125-129.

Bay, D., and Turner, R. (2009). Diversity and evolution of the small multidrug resistance protein family. BMC Evol. Biol. 9:140. doi: 10.1186/1471-21489-140

Beaber, J. W., Hochhut, B., and Waldor, M. K. (2004). SOS response promotes horizontal dissemination of antibiotic resistance genes. Nature 427, 72-74.

Beiko, R. G., Harlow, T. J., and Ragan, M. A. (2005). Highways of gene sharing in prokaryotes. Proc. Natl. Acad. Sci. U.S.A. 102, 14332-14337.

Bhullar, K., Waglechner, N., Pawlowski, A., Koteva, K., Banks, E. D., Johnston, M. D., et al. (2012). Antibiotic resistance is prevalent in an isolated cave microbiome. PLoS ONE 7:e34953. doi: 10.1371/journal.pone.0034953
Binh, C. T. T., Heuer, H., Kaupenjohann, M., and Smalla, K. (2009). Diverse aadA gene cassettes on class 1 integrons introduced into soil via spread manure. Res. Microbiol. 160, 427-433.

Bush, K., Courvalin, P., Dantas, G. Davies, J., Eisenstein, B., Huovinen, P., et al. (2011). Tackling antibiotic resistance. Nat. Rev. Microbiol. 9, 894-896.

Byrne-Bailey, K. G., Gaze, W. H., Kay, P., Boxall, A. B. A., Hawkey, P. M., and Wellington, E. M. H. (2009). Prevalence of sulfonamide resistance genes in bacterial isolates from manured agricultural soils and pig slurry in the United Kingdom. Antimicrob. Agents Chemother. 53, 696-702.

Cabello, F. C. (2006). Heavy use of prophylactic antibiotics in aquaculture: a growing problem for human and animal health and for the environment. Environ. Microbiol. 8, 1137-1144.

Chee-Sanford, J. C., Aminov, R. I., Krapac, I. J., Garrigues-Jeanjean, N., and Mackie, R. I. (2001). Occurrence and diversity of tetracycline resistance genes in lagoons and groundwater underlying two swine production facilities. Appl. Environ. Microbiol.67, 1494-1502.

Chee-Sanford, J. C., Mackie, R. I., Koike, S., Krapac, I. G., Lin, Y.-F., Yannarell, A. C., et al. (2009). Fate and transport of antibiotic residues and antibiotic resistance Ggenes following land application of manure waste. J. Environ. Qual. 38, 1086-1108.

Conway Morris, S. (2010). Evolution: like any other science it is predictable. Philos. Trans. R. Soc. Lond. B Biol. Sci. 365, 133-145.

Cordova-Kreylos, A. L., and Scow, K. M. (2007). Effects of ciprofloxacin on salt marsh sediment microbial communities. ISME J. 1, 585-595.

Costello, E. K., Stagaman, K., Dethlefsen, L., Bohannan, B. J. M., and Relman, D. A. (2012). The application of ecological theory toward an understanding of the human microbiome. Science 336, 1255-1262.

Couce, A., and Blázquez, J. (2009) Side effects of antibiotics on genetic variability. FEMS Microbiol. Rev. 33, 531-538.

Courvalin, P. (2008). Predictable and unpredictable evolution of antibiotic resistance. J. Intern. Med. 264, 4-16.

D’Costa, V. M., King, C. E., Kalan, L. Morar, M., Sung, W. W. L., Schwarz, C., et al. (2011). Antibiotic resistance is ancient. Nature 477, 457-461.

D'Costa, V. M., McGrann, K. M., Hughes, D. W., and Wright, G. D. (2006). Sampling the antibiotic resistome. Science 311, 374-377.
Dantas, G., and Sommer, M. O. A. (2012). Context matters-the complex interplay between resistome genotypes and resistance phenotypes. Curr. Opin. Microbiol. 15, 577-582.

Dantas, G., Sommer, M. O. A., Oluwasegun, R. D., and Church, G. M. (2008). Bacteria subsisting on antibiotics. Science 320, 100-103.

Datta, N., and Hughes, V. M. (1983). Plasmids of the same Inc groups in Enterobacteria before and after the medical use of antibiotics. Nature 306, 616-617.

Davies, J. (2007). Microbes have the last word. EMBO Rep. 8, 616-621.

Davies, J. (2011). How to discover new antibiotics: harvesting the parvome. Curr. Opin. Chem. Biol. 15, 5-10.

Davies, J., and Davies, D. (2010). Origins and evolution of antibiotic resistance. Microbiol. Mol. Biol. Rev. 74, 417-433.

Davies, J., and Ryan, K. S. (2011). Introducing the parvome: bioactive compounds in the microbial world. ACS Chem. Biol. 7, 252-259.

Davies, J., Spiegelman, G. B., and Yim, G. (2006). The world of subinhibitory antibiotic concentrations. Curr. Opin. Microbiol. 9, 445-453.

Desvaux, M., Parham, N. J., ScottTucker, A., and Henderson, I. R. (2004). The general secretory pathway: a general misnomer? Trends Microbiol. 12, 306-309.

Dethlefsen, L., Huse, S. M., Sogin, M. L. and Relman, D. A. (2008). The pervasive effects of an antibiotic on the human gut microbiota, as revealed by deep $16 \mathrm{~S}$ rRNA sequencing. PLoS Biol. 6:e280. doi: 10.1371/journal.pbio.0060280

Domingues, S., Harms, K., Fricke, W. F., Johnsen, P. J., da Silva, G. J., and Nielsen, K. M. (2012). Natural transformation facilitates transfer of transposons, integrons and gene cassettes between bacterial species. PLoS Pathog. 8:e1002837. doi: 10.1371/journal.ppat.1002837

Drudge, C. N., Elliott, A. V. C., Plach, J. M., Ejim, L. J., Wright, G. D., Droppo, I. G., et al. (2012). Diversity of integron- and culture-associated antibiotic resistance genes in freshwater floc. Appl. Env. Microbiol. 78, 4367-4372.

Earl, D. J., and Deem, M. W. (2004). Evolvability is a selectable trait. Proc Natl. Acad. Sci. U.S.A. 101, 1153111536.

Fajardo, A., Linares, J. F., and Martínez, J. L. (2009). Towards an ecological approach to antibiotics and antibiotic resistance genes. Clin. Microbiol. Infect. 15, 14-16.
Fajardo, A., and Martínez, J. L. (2008). Antibiotics as signals that trigger specific bacterial responses. Curr. Opin. Microbiol. 11, 161-167.

Fischbach, M. A., Walsh, C. T., and Clardy, J. (2008). The evolution of gene collectives: how natural selection drives chemical innovation. Proc. Natl. Acad. Sci. U.S.A. 105, 46014608.

Fondi, M., and Fani, R. (2010). The horizontal flow of the plasmid resistome: clues from inter-generic similarity networks. Environ. Microbiol. 12, 3228-3242.

Forsberg, K. J., Reyes, A., Wang, B., Selleck, E. M., Sommer, M. O. A., and Dantas, G. (2012). The shared antibiotic resistome of soil bacteria and human pathogens. Science 337, 1107-1111.

Fournier, P.-E., Vallenet, D., Barbe, V., Audic, S., Ogata, H., Poirel, L., et al. (2006). Comparative genomics of multidrug resistance in Acinetobacter baumannii. PLoS Genet. 2:e7. doi: 10.1371/journal.pgen.0020007

Garriss, G., Waldor, M. K., and Burrus, V. (2009). Mobile antibiotic resistance encoding elements promote their own diversity. PLoS Genet. 5:e1000775. doi: 10.1371/ journal.pgen.1000775

Gaze, W. H., Abdouslam, N., Hawkey, P. M., and Wellington, E. M. H. (2005). Incidence of class 1 integrons in a quaternary ammonium compoundpolluted environment. Antimicrob. Agents Chemother. 49, 1802-1807.

Gaze, W. H., Zhang, L., Abdouslam, N. A., Hawkey, P. M., Calvo-Bado, L., Royle, J., et al. (2011). Impacts of anthropogenic activity on the ecology of class 1 integrons and integronassociated genes in the environment. ISME J. 5, 1253-1261.

Gillings, M., Boucher, Y., Labbate, M., Holmes, A., Krishnan, S., Holley, M., etal. (2008a). The evolution of class 1 integrons and the rise of antibiotic resistance. J. Bacteriol. 190, 5095-5100.

Gillings, M. R., Xuejun, D., Hardwick, S. A., Holley, M. P., and Stokes, H. W. (2008b). Gene cassettes encoding resistance to quaternary ammonium compounds: a role in the origin of clinical class 1 integrons? ISME J. 3, 209-215.

Gillings, M. R., Holley, M. P., and Stokes, H. W. (2009a). Evidence for dynamic exchange of qac gene cassettes between class 1 integrons and other integrons in freshwater biofilms. FEMS Microbiol. Lett. 296, 282-288.

Gillings, M. R., Labbate, M., Sajjad, A., Giguere, N. J., Holley, M. P., and 
Stokes, H. W. (2009b). Mobilization of a Tn402-like class 1 integron with a novel cassette array via flanking miniature inverted-repeat transposable element-like structures. Appl. Environ. Microbiol. 75, 6002-6004.

Gillings, M. R., and Stokes, H. W. (2012). Are humans increasing bacterial evolvability? Trends Ecol. Evol. 27, 346-352.

Goh, E.-B., Yim, G., Tsui, W., McClure, J., Surette, M. G., and Davies, J. (2002). Transcriptional modulation of bacterial gene expression by subinhibitory concentrations of antibiotics. Proc. Natl. Acad. Sci. U.S.A. 99, 17025-17030.

Graham, D. W., Olivares-Rieumont, S., Knapp, C. W., Lima, L., Werner, D., and Bowen, E. (2011). Antibiotic resistance gene abundances associated with waste discharges to the Almendares River near Havana, Cuba. Environ. Sci. Technol. 45, 418-424.

Hall, B. G., and Barlow, M. (2004). Evolution of the serine $\beta$-lactamases: past, present and future. Drug Resist. Updat. 7, 111-123.

Hardwick, S. A., Stokes, H. W., Findlay, S., Taylor, M., and Gillings, M. R. (2008). Quantification of class 1 integron abundance in natural environments using real-time quantitative PCR. FEMS Microbiol. Lett. 278, 207-212.

Hegstad, K., Langsrud, S., Lunestad, B. T., Scheie, A. A., Sunde, M., and Yazdankhah, S. P. (2010). Does the wide use of quaternary ammonium compounds enhance the selection and spread of antimicrobial resistance and thus threaten our health? Microb. Drug Resist. 16, 91-104.

Henke, J. M., and Bassler, B. L. (2004). Bacterial social engagements. Trends Cell Biol. 14, 648-656.

Heuer, H., Schmitt, H., and Smalla, K. (2011). Antibiotic resistance gene spread due to manure application on agricultural fields. Curr. Opin. Microbiol. 14, 236-243.

Hoffman, L. R., D’Argenio, D. A., MacCoss, M. J., Zhang, Z., Jones, R. A., and Miller, S. I. (2005). Aminoglycoside antibiotics induce bacterial biofilm formation. Nature 436, 1171 1175.

Huang, F., Haydock, S. F., Mironenko, T., Spiteller, D., Li, Y., and Spencer, J. B. (2005). The neomycin biosynthetic gene cluster of Streptomyces fradiae NCIMB 8233: characterisation of an aminotransferase involved in the formation of 2-deoxystreptamine. Org. Biomol. Chem. 3, 1410-1418.

Hughes, V. M., and Datta, N. (1983). Conjugative plasmids in bacteria of the 'pre-antibiotic' era. Nature 302, 725-726.

Jakobsson, H. E., Jernberg, C., Andersson, A. F., Sjölund-Karlsson, M., Jansson, J. K., and Engstrand, L. (2010). Short-term antibiotic treatment has differing long-term impacts on the human throat and gut microbiome. PLOS ONE 5:e9836. doi: 10.1371/journal.pone.0009836

Klockgether, J., Cramer, N., Wiehlmann, L., Davenport, C. F., and Tummler, B. (2011). Pseudomonas aeruginosa genomic structure and diversity. Front. Microbiol. 2:150. doi 10.3389/fmicb.2011.00150

Kloesges, T., Popa, O., Martin, W., and Dagan, T. (2010). Networks of gene sharing among 329 Proteobacterial genomes reveal differences in lateral gene transfer frequency at different phylogenetic depths. Mol. Biol. Evol. 28, 1057-1074.

Knapp, C. W., Dolfing, J., Ehlert, P. A. I., and Graham, D. W. (2009). Evidence of increasing antibiotic resistance gene abundances in archived soils since 1940. Environ. Sci. Technol. 44, 580-587.

Knapp, C. W., Engemann, C. A., Hanson, M. L., Keen, P. L., Hall, K. J., and Graham, D. W. (2008). Indirect evidence of transposon-mediated selection of antibiotic resistance genes in aquatic systems at low-level oxytetracycline exposures. Environ. Sci. Technol. 42, 5348-5353.

Kohanski, M. A., DePristo, M. A. and Collins, J. J. (2010). Sublethal antibiotic treatment leads to multidrug resistance via radical-induced mutagenesis. Mol. Cell 37, 311-320.

Kong, W. D., Zhu, Y. G., Fu, B. J., Marschner, P., and $\mathrm{He}$, J. Z. (2006). The veterinary antibiotic oxytetracycline and $\mathrm{Cu}$ influence functional diversity of the soil microbial community. Environ. Pollut. 143 129-137.

Kristiansson, E., Fick, J., Janzon, A. Grabic, R., Rutgersson, C., Weijdegard, B., etal. (2011). Pyrosequencing of antibiotic-contaminated river sediments reveals high levels of resistance and gene transfer elements. PLOS ONE 6:e17038, doi: 10.1371/journal.pone.0017038

Krizova, L., Dijkshoorn, L., and Nemec, A. (2011). Diversity and evolution of AbaR genomic resistance islands in Acinetobacter baumannii strains of European clone I. Antimicrob. Agents Chemother. 55, 3201-3206.

Kuete, V., Alibert-Franco, S., Eyong, K. O., Ngameni, B., Folefoc, G. N., Nguemeving, J. R., et al. (2011). Antibacterial activity of some natural products against bacteria expressing a multidrug-resistant phenotype. Int J. Antimicrob. Agents 37, 156-161.

Lapierre, P., and Gogarten, J. P. (2009). Estimating the size of the bacterial pan-genome. Trends Genet. 25, 107-110.

Le-Minh, N., Khan, S. J., Drewes, J. E., and Stuetz, R. M. (2010). Fate of antibiotics during municipal water recycling treatment processes. Water Res. 44, 4295-4323.

Leplae, R., Lima-Mendez, G., and Toussaint, A. (2010). ACLAME: a CLAssification of Mobile genetic Elements, update 2010. Nucleic Acids Res. 38, D57-D61.

Li, D., Yang, M., Hu, J., Zhang, J., Liu, R., Gu, X., et al. (2009). Antibioticresistance profile in environmental bacteria isolated from penicillin production wastewater treatment plant and the receiving river. Environ. Microbiol. 11, 1506-1517.

Li, D., Yu, T., Zhang, Y., Yang, M., Li, Z., Liu, M., et al. (2010). Antibiotic resistance characteristics of environmental bacteria from an oxytetracycline production wastewater treatment plant and the receiving river. Appl. Environ. Microbiol. 76, 3444-3451.

Lin, J. T., Connelly, M. B., Amolo, C., Otani, S., and Yaver, D. S. (2005). Global transcriptional response of Bacillus subtilis to treatment with subinhibitory concentrations of antibiotics that inhibit protein synthesis. Antimicrob. Agents Chemother. 49, 1915-1926.

Linares, J. F., Gustafsson, I., Baquero, F. and Martinez, J. L. (2006). Antibiotics as intermicrobial signaling agents instead of weapons. Proc. Natl. Acad. Sci. U.S.A. 103, 19484-19489.

Liu, B., and Pop, M. (2009). ARDB antibiotic resistance genes database. Nucleic Acids Res. 37, D443-D447.

Lupo, A., Coyne, S., and Berendonk, T. U. (2012). Origin and evolution of antibiotic resistance: the common mechanisms of emergence and spread in water bodies. Front. Microbiol. 3:18. doi: 10.3389/ fmicb.2012.00018

Lyon, G. J., and Muir, T. W. (2003). Chemical signaling among bacteria and its inhibition. Chem. Biol. 10, 1007-1021.

Marr, A. K., Overhage, J., Bains, M. and Hancock, R. E. W. (2007). The Lon protease of Pseudomonas aeruginosa is induced by aminoglycosides and is involved in biofilm formation and motility. Microbiology 153, 474-482.

Martinez, J. L. (2008). Antibiotics and antibiotic resistance genes in natural environments. Science 321, 365-367.
Martinez, J. L. (2009a). Environmental pollution by antibiotics and by antibiotic resistance determinants. Environ. Pollut. 157, 2893-2902.

Martinez, J. L. (2009b). The role of natural environments in the evolution of resistance traits in pathogenic bacteria. Proc. R. Soc. B Biol. Sci. 276, 2521-2530.

Martinez, J. L. (2012). Natural antibiotic resistance and contamination by antibiotic resistance determinants: the two ages in the evolution of resistance to antimicrobials. Front. Microbiol. 3:1. doi: 10.3389/ fmicb.2012.00001

Martinez, J. L., Baquero, F., and Andersson, D. I. (2007). Predicting antibiotic resistance. Nat. Rev. Microbiol. 5 958-965.

Martinez, J. L., Fajardo, A., Garmendia, L., Hernandez, A., Linares, J. F., Martínez-Solano, L., et al. (2009a). A global view of antibiotic resistance. FEMS Microbiol. Rev. 33, 44-65.

Martinez, J. L., Sánchez, M. B. Martínez-Solano, L., Hernandez, A., Garmendia, L., Fajardo, A., et al. (2009b). Functional role of bacterial multidrug efflux pumps in microbial natural ecosystems. FEMS Microbiol. Rev. 33, 430-449.

Medini, D., Donati, C., Tettelin, H., Masignani, V., and Rappuoli, R. (2005). The microbial pangenome. Curr. Opin. Genet. Dev. 15, 589-594.

Méndez, C., and Salas, J. A. (2001). The role of ABC transporters in antibiotic-producing organisms: drug secretion and resistance mechanisms. Res. Microbiol. 152, 341-350.

Moura, A., Henriques, I., Smalla, K., and Correia, A. (2010). Wastewater bacterial communities bring together broad-host range plasmids, integrons and a wide diversity of uncharacterized gene cassettes. Res. Microbiol. 161, 58-66.

Nagachinta, S., and Chen, J. (2008). Transfer of class 1 integron-mediated antibiotic resistance genes from shiga toxin-producing Escherichia coli to a susceptible E. coli K-12 strain in storm water and bovine feces. Appl. Environ. Microbiol. 74, 50635067.

Nardelli, M., Scalzo, P. M., Ramírez, M. S., Quiroga, M. P., Cassini, M. H., and Centrón, D. (2012). Class 1 integrons in environments with different degrees of urbanization. PLoS ONE 7:e39223. doi: 10.1371/journal.pone.0039223

Nogueira, T., Rankin, D. J., Touchon, M., Taddei, F., Brown, S. P., and Rocha, E. P. C. (2009). Horizontal gene transfer of the secretome drives 
the evolution of bacterial cooperation and virulence. Curr. Biol. 19 1683-1691.

Norman, A., Hansen, L. H., and Sorensen, S. J. (2009). Conjugative plasmids: vessels of the communal gene pool. Philos. Trans. R. Soc. Lond. B Biol. Sci. 364, 2275-2289.

Pallecchi, L., Bartoloni, A., Paradisi, F., and Rossolini, G. M. (2008). Antibiotic resistance in the absence of antimicrobial use: mechanisms and implications. Expert Rev. Anti Infect. Ther. 6, 725-732.

Palumbi, S. R. (2001). Humans as the world's greatest evolutionary force. Science 293, 1786-1790.

Paulsen, I. T., Skurray, R. A., Tam, R., Saier, M. H., Turner, R. J., Weiner, J. H., etal. (1996). The SMR family: a novel family of multidrug efflux proteins involved with the efflux of lipophilic drugs. Mol. Microbiol. 19, 1167-1175.

Pei, R., Kim, S.-C., Carlson, K. H., and Pruden, A. (2006). Effect of river landscape on the sediment concentrations of antibiotics and corresponding antibiotic resistance genes (ARG). Water Res. 40, 2427-2435

Pellegrini, C., Celenza, G., Segatore, B., Bellio, P., Setacci, D., Amicosante, G., et al. (2011). Occurrence of class 1 and 2 integrons in resistant Enterobacteriaceae collected from a urban wastewater treatment plant: first report from Central Italy. Microb. Drug Resist. 17, 229-234.

Pellegrini, C., Mercuri, P. S., Celenza, G., Galleni, M., Segatore, B., Sacchetti, E., etal. (2009). Identification of blaIMP-22 in Pseudomonas spp. in urban wastewater and nosocomial environments: biochemical characterization of a new IMP metalloenzyme variant and its genetic location. J. Antimicrob. Chemother. 63, 901-908.

Petković, H., Cullum, J., Hranueli, D., Hunter, I. S., Perić-Concha, N., Pigac, J., etal. (2006). Genetics of Streptomyces rimosus, the oxytetracycline producer. Microbiol. Mol. Biol. Rev. 70, 704-728.

Piddock, L. J. V. (2006). Multidrugresistance efflux pumps? not just for resistance. Nat. Rev. Microbiol. 4, 629-636.

Pigliucci, M. (2008). Is evolvability evolvable? Nat. Rev. Genet. 9, 75-82.

Poole, K. (2005). Efflux-mediated antimicrobial resistance. J. Antimicrob. Chemother. 56, 20-51.

Pootoolal, J., Thomas, M. G., Marshall, C. G., Neu, J. M., Hubbard, B. K., Walsh, C. T., et al. (2002). Assembling the glycopeptide antibiotic scaffold: the biosynthesis of from Streptomyces toyocaensis NRRL15009. Proc. Natl. Acad. Sci. U.S.A. 99, 8962-8967.

Popa, O., and Dagan, T. (2011). Trends and barriers to lateral gene transfer in prokaryotes. Curr. Opin. Microbiol. 14, 615-623.

Popa, O., Hazkani-Covo, E., Landan, G. Martin, W., and Dagan, T. (2011). Directed networks reveal genomic barriers and DNA repair bypasses to lateral gene transfer among prokaryotes. Genome Res. 21, 599-609.

Pruden, A., Pei, R., Storteboom, H., and Carlson, K. H. (2006). Antibiotic resistance genes as emerging contaminants: studies in Northern Colorado. Environ. Sci. Technol. 40, 74457450.

Prudhomme, M., Attaiech, L., Sanchez, G., Martin, B., and Claverys, J.-P. (2006). Antibiotic stress induces genetic transformability in the human pathogen Streptococcus pneumoniae. Science 313, 89-92.

Riesenfeld, C. S., Goodman, R. M., and Handelsman, J. (2004). Uncultured soil bacteria are a reservoir of new antibiotic resistance genes. Environ. Microbiol. 6, 981-989.

Rosewarne, C. P., Pettigrove, V., Stokes H. W., and Parsons, Y. M. (2010). Class 1 integrons in benthic bacterial communities: abundance, association with Tn402-like transposition modules and evidence for coselection with heavy-metal resistance. FEMS Microbiol. Ecol. 72, 35-46.

Ryan, R. P., and Dow, J. M. (2008). Diffusible signals and interspecies communication in bacteria. Microbiology 154, 1845-1858.

Salyers, A., and Shoemaker, N. B. (2006). Reservoirs of antibiotic resistance genes. Anim. Biotechnol. 17, 137-146.

Sarmah, A. K., Meyer, M. T., and Boxall, A. B. A. (2006). A global perspective on the use, sales, exposure pathways, occurrence, fate and effects of veterinary antibiotics (VAs) in the environment. Chemosphere 65, 725-759.

Schlacher, K., and Goodman, M. F. (2007). Lessons from 50 years of SOS DNA-damage-induced mutagenesis. Nat. Rev. Mol. Cell Biol. 8, 587-594.

Schlüter, A., Krause, L., Szczepanowski, R., Goesmann, A., and Pühler, A. (2008). Genetic diversity and composition of a plasmid metagenome from a wastewater treatment plant. $J$. Biotechnol. 136, 65-76.

Segura, P. A., Francois, M., Gagnon, C., and Sauve, S. (2009). Review of the occurrence of anti-infectives in contaminated wastewaters and natural and drinking waters. Environ. Health Perspect. 117, 675-684.
Seshasayee, A. S. N., Bertone, P., Fraser G. M., and Luscombe, N. M. (2006) Transcriptional regulatory networks in bacteria: from input signals to output responses. Curr. Opin. Microbiol. 9, 511-519.

Shank, E. A., and Kolter, R. (2009). New developments in microbial interspecies signaling. Curr. Opin. Microbiol. 12, 205-214.

Siefert, J. L. (2009). "Defining the Mobilome," in Horizontal Gene Transfer: Genomes in Flux, eds M. B. Gogarten, J. P. Gogarten, and L. C. Olendzenski (New York: Humana Press), 13-27.

Sjolund, M., Bonnedahl, J., Hernandez, J., Bengtsson, S., Cederbrant, G. Pinhassi, J., et al. (2008). Dissemination of multidrug-resistant bacteria into the Arctic. Emerg. Infect. Dis. 14, $70-72$.

Skippington, E., and Ragan, M. A (2011). Lateral genetic transfer and the construction of genetic exchange communities. FEMS Microbiol. Rev. 35, 707-735.

Skurnik, D., Ruimy, R., Andremont, A., Amorin, C., Rouquet, P., Picard, B. et al. (2006). Effect of human vicinity on antimicrobial resistance and integrons in animal faecal Escherichia coli. J. Antimicrob. Chemother. 57, 1215-1219.

Sommer, M. O. A., and Dantas, G. (2011). Antibiotics and the resistant microbiome. Curr. Opin. Microbiol. $14,556-563$.

Sorensen, S. J., Bailey, M., Hansen, L. H., Kroer, N., and Wuertz, S. (2005). Studying plasmid horizontal transfer in situ: a critical review. Nat. Rev. Microbiol. 3, 700-710.

Stepanauskas, R., Glenn, T. C., Jagoe, C. H., Tuckfield, R. C., Lindell, A H., King, C. J., et al. (2006). Coselection for microbial resistance to metals and antibiotics in freshwater micro cosms. Environ. Microbiol. 8, 15101514.

Stevens, A. M., Schuster, M., and Rumbaugh, K. P. (2012). Working together for the common good: cell-cell communication in bacteria. J. Bacteriol. 194, 2131-2141.

Stokes, H. W., and Gillings, M. R. (2011). Gene flow, mobile genetic elements and the recruitment of antibiotic resistance genes into Gram-negative pathogens. FEMS Microbiol. Rev. 35, 790-819.

Storteboom, H., Arabi, M., Davis J. G., Crimi, B., and Pruden, A. (2010). Identification of antibioticresistance-gene molecular signatures suitable as tracers of pristine river urban, and agricultural sources. Env iron. Sci. Technol. 44, 1947-1953.
Szczepanowski, R., Braun, S., Riedel, V., Schneiker, S., Krahn, I., Puhler, A., et al. (2005). The 120592bp IncF plasmid pRSB107 isolated from a sewage-treatment plant encodes nine different antibiotic-resistance determinants, two iron-acquisition systems and other putative virulenceassociated functions. Microbiology 151, 1095-1111.

Taylor, N. G. H., Verner-Jeffreys, D. W., and Baker-Austin, C. (2011). Aquatic systems: maintaining, mixing and mobilising antimicrobial resistance? Trends Ecol. Evol. 26, 278-284.

Tenaillon, O., Denamur, E., and Matic, I. (2004). Evolutionary significance of stress-induced mutagenesis in bacteria. Trends Microbiol. 12, 264-270.

Tennstedt, T., Szczepanowski, R., Braun, S., Pühler, A., and Schlüter, A. (2003). Occurrence of integron-associated resistance gene cassettes located on antibiotic resistance plasmids isolated from a wastewater treatment plant. FEMS Microbiol. Ecol. 45, 239-252.

Tettelin, H., Riley, D., Cattuto, C., and Medini, D. (2008). Comparative genomics: the bacterial pan-genome. Curr. Opin. Microbiol. 11, 472-477.

Thaller, M. C., Migliore, L., Marquez, C., Tapia, W., Cede $\tilde{A} \pm$, V., Rossolini, G. M., et al. (2010). Tracking acquired antibiotic resistance in commensal bacteria of Galapagos land iguanas: no man, no resistance. PLOS ONE 5:e8989. doi: 10.1371/journal.pone.0008989

Thi, T. D., Lopez, E., Rodriguez-Rojas, A., Rodriguez-Beltran, J., Couce, A., Guelfo, J. R., etal. (2011). Effect of recA inactivation on mutagenesis of Escherichia coli exposed to sublethal concentrations of antimicrobials. J. Antimicrob. Chemother. 66, 531-538.

Thomas, C. M., and Nielsen, K. M. (2005). Mechanisms of, and barriers to, horizontal gene transfer between bacteria. Nat. Rev. Microbiol. 3, 711-721.

Toleman, M. A., and Walsh, T. R. (2011). Combinatorial events of insertion sequences and ICE in Gram-negative bacteria. FEMS Microbiol. Rev. 35, 912-935.

Toussaint, A., and Chandler, M. (2012). "Prokaryote genome fluidity: toward a system approach of the mobilome," in Bacterial Molecular Networks, eds J. Helden, A. Toussaint and D. Thieffry (New York: Springer), 57-80.

Tsui, W. H. W., Yim, G., Wang, H. H., McClure, J. E., Surette, M. G., and Davies, J. (2004). Dual effects of MLS antibiotics: transcriptional modulation and interactions on the 
Billings

Humans, antibiotics and evolution

ribosome. Chem. Biol. 11, 13071316.

Úbeda, C., Marques, E., Knecht, E., Lava, I.., Novick, R. P., and Penadés, J. R. (2005). Antibiotic-induced SOS response promotes horizontal dissemination of pathogenicity island-encoded virulence factors in staphylococci. Mol. Microbial. 56, 836-844.

Waksman, S. A. (1973). History of the word 'Antibiotic'. J. Hist. Med. Allied Sci. 28, 284-286.

Watkinson, A. J., Murby, E. J., and Costanzo, S. D. (2007). Removal of antibiotics in conventional and advanced wastewater treatment: implications for environmentall discharge and wastewater recycling. Water Res. 41, 41644176.

Whitman, W. B., Coleman, D. C., and Wiebe, W. J. (1998). Prokaryotes: the unseen majority. Proc.
Natl. Acad. Sci. U.S.A. 95, 65786583.

Wright, G. D. (2007). The antibiotic resistome: the nexus of chemical and genetic diversity. Nat. Rev. Microbial. 5, 175-186.

Wright, G. D. (2010). The antibiotic resistome. Expert Spin. Drug Discov. 5, 779-788.

Wright, M. S., Baker-Austin, C., Lindell, A. H., Stepanauskas, R., Stokes, H. W., and McArthur, J. V. (2008). Influence of industrial contaminaion on mobile genetic elements: class 1 integron abundance and gene cassette structure in aquatic bacterial communities. ISME J. 2, 417-428.

Yin, G., Huimi Wang, H., and Davies, J. (2007). Antibiotics as signalling molecules. Philos. Trans. R. Soc. Lond. B Biol. Sci. 362, 1195-1200.

Zgurskaya, H. I., and Nikaido, H. (2000). Multidrug resistance mechanisms: drug efflux across two membranes. Mol. Microbial. 37, 219-225.

Chang, X.-X., Zhang, T., Zhang, M., Fang, H., and Cheng, S.-P. (2009). Characterization and quantification of class 1 integrons and associated gene cassettes in sewage treatment plants. Appl. Microbiol. Biotechnol. 82, 1169-1177.

Zuccato, E., Castiglioni, S., Bagnati, R., Melis, M., and Fanelli, R. (2010). Source, occurrence and fate of antibiotics in the Italian aquatic environment. J. Hazard. Mater. 179, 1042-1048.

Conflict of Interest Statement: The author declares that the research was conducted in the absence of any commercial or financial relationships that could be construed as a potential conflick of interest.
Received: 25 October 2012; paper pending published: 11 December 2012; accepted: 03 January 2013; published online: 22 January 2013.

Citation: Fillings MR (2013) Evolutioncary consequences of antibiotic use for the resistome, mobilome, and microbial pangenome. Front. Microbic. 4:4. do: 10.3389/fmicb.2013.00004

This article was submitted to Fromtiers in Antimicrobials, Resistance and Chemotherapy, a specialty of Frontiers in Microbiology.

Copyright (c) 2013 Fillings. This is an open-access article distributed under the terms of the Creative Commons Attribution License, which permits use, distribution and reproduction in other forums, provided the original authors and source are credited and subject to any copyright notices concerning any thirdparty graphics etc.

Frontiers in Microbiology | Antimicrobials, Resistance and Chemotherapy

January 2013 | Volume 4 | Article 4 | 10 